\title{
A INICIAÇÃO NA DOCÊNCIA: ANALISANDO EXPERIÊNCIAS DE ALUNOS PROFESSORES DAS LICENCIATURAS
}

\section{STARTING TEACHING: ANALYZING LICENCIA- TESHIP STUDENT TEACHERS' EXPERIENCES}

\author{
Josilene Silva da COSTA* \\ Rosa Maria Moraes Anunciato de OLIVEIRA**
}

Resumo: A iniciação na docência tem se revelado como uma etapa importante no processo de aprender a ser professor. Diante de uma realidade complexa, o professor se desestrutura, pensa em desistir da profissão, duvida da sua competência e da importância da formação inicial. Para aqueles que permanecem, é uma fase que contribui de maneira singular para uma determinada forma de ser professor. Compreendemos como uma tarefa urgente e complexa o pensar e propor alternativas de formação que atendam às necessidades do professor no início da profissão. Possivelmente, um passo importante seja buscar nos cursos de formação inicial a perspectiva dos alunos que já são professores. Diversos cursos de licenciatura de universidades brasileiras são freqüentados por alunos que aprendem a profissão docente na universidade e na escola ao mesmo tempo. O estudo desse perfil de estudante, realizado junto a alunos professores dos cursos de Letras e de Matemática de uma instituição pública de ensino superior, amplia a nossa compreensão sobre o processo de formação de professores na universidade. A análise das experiências de início da carreira fornece elementos para se repensar a formação inicial e estreitar os vínculos dessa formação com a escola básica - local

\footnotetext{
* Mestre em Educação, professora da Universidade Estadual do Sudoeste da Bahia, doutoranda do Programa de Pós- Graduação em Educação da Universidade Federal de São Carlos. E-mail: josycosta9@hotmail.com

* Doutora em Educação, professora do Programa de Pós-Graduação da Universidade Federal de São Carlos. E-mail: rosa@power.ufscar.br
} 
de exercício profissional. Os resultados apontam para a necessidade de a universidade ultrapassar a perspectiva de certificação e assumir uma postura mais solidária e mais comprometida com a escola básica e com o professor que se faz cotidianamente dentro dela.

Palavras-Chave: Formação de professores. Alunos professores. Professores iniciantes.

Abstract: The beginning of teaching has proved to be an important stage in the process of learning to be a teacher. In face of this complex reality, teachers loose balance and think about giving up the profession, have doubts about their competence and question their initial education. For those who stay in the profession, the beginning of teaching it is a stage that contributes in an especial way to how teachers develop a certain form of teaching. It is recognized urgent and complex task to think and propose alternative teacher education approaches that meet the needs of teachers who are starting in the profession. It is possible that one of the first steps is to consider the perspective of the students who already teach when they are start their initial teacher education. Many teacher education courses are attended by students who learn the profession at the university and in the schools at the same time. The study of the profile of this kind of students along with student teachers of the Languages and Math courses in a public institution of higher education broadened our understanding about the process of teacher education at the universities. The analysis of the experiences of those in the beginning of the career provides us with elements to re-think initial education and straightens the bonds of this level of education with basic education - locus of the profession. The results point to the need for universities to overcome the certification perspective and to assume a more solidary and compromised approach with basic education and with teachers that are part of its daily routine. 
Keywords: Teacher Education. Student teachers. Beginning teacher.

\section{FORMAÇÃO DE PROFESSORES: PRIMEIRAS PALAVRAS}

Nas últimas décadas a formação de professores para atuação na Educação Básica tem sido objeto de estudo, havendo ampliação desse campo de discussão e sendo reveladas diferentes concepções sobre essa formação. Temos hoje uma produção teórica que enfatiza o processo de aprendizagem profissional da docência e seus saberes, tendo como foco principal a figura do professor.

Esses estudos articulam-se em torno dos processos de aprender a ensinar e estão abrigados sob a denominação do Paradigma do Pensamento do Professor (MARCELO, 1998), valorizando a prática como espaço de reflexão e construção de saberes e compreendendo a aprendizagem profissional da docência como um processo que ocorre ao longo da carreira (IMBERNÓN, 2000; MIZUKAMI, 1996; NÓVOA, 1992 e 1995; SCHÖN, 1992; TARDIF, 2OOO; TARDIF \& RAYMOND, 2000; entre outros).

Ao eleger como objeto de pesquisa o pensamento do professor, seus saberes, suas histórias de vida, suas crenças, concepções e conhecimentos, tais estudos dão "poder" ao professor em relação à própria profissão, discutem o conhecimento específico da docência e possibilitam a análise de teorias implícitas, a partir do momento em que as mesmas se constituem em objeto de estudo e reflexão.

A riqueza e amplidão da produção teórica têm contribuído para produzir inquietações e preocupações com as mudanças a serem empreendidas na formação inicial nos cursos de licenciatura, porém não têm, ainda, resultado em mudanças significativas no modelo de formação instituído em tais cursos, como nos indicam os estudos de Candau (1999); Pereira (2000); Santos (1994; 2000).

A profissionalização docente ocorre num processo contínuo e abarca experiências e saberes diversos, que vão garantindo ao professor o domínio do trabalho e de si mesmo (TARDIF, 2000). Compreendemos que a formação inicial é um suporte fundamental para o desenvolvimento profissional. Na perspectiva da formação como processo, o caráter conclusivo ainda atribuído a essa etapa formativa não tem mais lugar. Imbernón (2000) considera que a formação inicial, como tem ocorrido, 
(...) não oferece preparo suficiente para aplicar uma nova metodologia, nem para aplicar métodos desenvolvidos teoricamente na prática da sala de aula. Além disso, não se tem a menor informação sobre como desenvolver, implantar e avaliar processos de mudança. E essa formação inicial é muito importante já que é o início da profissionalização, um período em que as virtudes, os vícios, as rotinas etc. são assumidos como processos usuais da profissão (p.41).

O autor defende, ainda, a idéia de que essa formação deve possibilitar aos professores o domínio "de uma bagagem sólida nos âmbitos científico, cultural, contextual, psicopedagógico e pessoal" (p.60-61), deixando clara a sua posição sobre o lugar da formação inicial no processo de desenvolvimento profissional dos professores.

Tendo como foco a carreira docente, o estudo de Huberman (1995) analisa o ciclo de vida profissional de professores do ensino secundário e afirma que "para alguns, esse processo pode parecer linear, mas, para outros, há patamares, regressões, becos sem saída, momentos de arranque, descontinuidades" (p.38). Aponta algumas fases: Entrada na carreira, Tateamento (três primeiros anos); Estabilização, Consolidação de um repertório pedagógico (entre quatro e seis anos); Diversificação, Ativismo (entre os sete e os vinte e cinco anos); Serenidade, Distanciamento afetivo ou Conservantismo (entre vinte e cinco e trinta e cinco anos) e Desinvestimento - sereno ou amargo (entre os trinta e cinco e quarenta anos). Para o autor essa seqüência não é universal e seu transcurso não é determinado apenas pelo tempo de carreira nem independente de condições sociais e do período histórico.

A entrada na carreira, segundo Huberman (1995), é marcada pelo aspecto da "sobrevivência" e da "descoberta". A "sobrevivência" está relacionada ao "choque com a realidade", definido por Veenman (1984 apud ESTEVE, 1995, p.109) como “(...) o colapso das idéias missionárias forjadas durante o curso de formação de professores, em virtude da dura realidade da vida quotidiana na sala de aula". A confrontação com a realidade profissional, com a complexidade das situações que marcam o exercício da docência, são aspectos marcantes da iniciação profissional docente.

Nesse momento, o aspecto da "descoberta" também se faz 
presente através do entusiasmo, da experimentação, da responsabilidade, do sentimento de fazer parte de um grupo profissional. Segundo dados da literatura, Huberman (ibid., p.37) explica que alguns perfis podem apresentar apenas um desses aspectos como dominante. Outros podem vivê-los em paralelo e aí a "descoberta" é que permite suportar o "choque com a realidade". A "exploração", que para o autor “(...) consiste em fazer uma opção provisória, em proceder a uma investigação dos contornos da profissão, experimentando um ou mais papéis", seria comum aos diferentes perfis.

Cavaco (1995) estudou o desenrolar da vida pessoal e profissional de diversos docentes e também destaca que na fala deles essa experiência é sempre descrita com "grande riqueza de pormenores, expressividade e proximidade emotiva”. Revela que alguns esquemas de ação desse primeiro momento permanecem e são utilizados no enfrentamento dos problemas cotidianos. A autora também reafirma que as contradições, a insegurança, a necessidade de pertencimento marcam essa fase. Nas suas palavras:

O início da atividade profissional é, para todos os indivíduos, um período contraditório. Se, por um lado, o ter encontrado um lugar, um espaço na vida activa, corresponde à confirmação da idade adulta, ao reconhecimento do valor da participação pessoal no universo do trabalho, à perspectiva da construção da autonomia, por outro, as estruturas ocupacionais raramente correspondem à identidade vocacional definida nos bancos da escola, ou através das diferentes actividades socioculturais, ou modelada pelas expectativas familiares. Assim, é no jogo de procura de conciliação, entre aspirações e projectos e as estruturas profissionais, que o jovem professor tem de procurar o seu próprio equilíbrio dinâmico, reajustar, mantendo, o sonho que dá sentido aos seus esforços. (p.162-163)

O sentimento de pertencimento profissional vai sendo construído ao longo do tempo e é marcado pelo contexto de trabalho e de vida do professor. A inserção numa carreira é um momento importante, pois marca o início da socialização profissional e é nesse processo que o saber ser e o saber fazer serão incorporados pelos professores (TARDIF \& RAYMOND, 2OOO).

Moraes (2006), em estudo que trata do processo de aprendizagem da docência, enfocando professores de um curso pré-vestibular, 
evidencia o caráter contínuo do desenvolvimento profissional docente. Em relação ao início da docência, a autora diz que os relatos dos professores apontam para:

(...) a influência de elementos da experiência adquirida como alunos, em todos os níveis de ensino, não necessariamente a mais recente, mas as experiências mais significativas (...). Com base nesse saber é que os professores sentem-se mais ou menos autônomos ou seguros e independentes para agirem como agem e tomarem as decisões que tomam no cotidiano da sala de aula, seja no planejamento ou na condução de suas aulas. (p.121)

Esse e outros estudos (MIZUKAMI, 2000; MIZUKAMI et al., 2002; NÓVOA, 1992) nos mostram que também a prática vai se constituindo como lugar onde se aprende e se constroem os saberes da profissão. Nesse processo de aprendizagem, entre as dificuldades vivenciadas no início da docência, Moraes (ibid., 2006) relata que o domínio do conteúdo específico da área em que atuam e a conseqüente seleção dos professores para ensinar se constituem numa grande preocupação da maioria dos que participaram do seu estudo. Com base em Knowles (1994), a autora percebe que nos primeiros anos os professores focalizam a sua atenção no "aprender a ensinar", mais que no "aprender a ser professor", que demanda aprendizagens que extrapolam o espaço da sala de aula.

A iniciação na docência tem se revelado como uma etapa importante no processo de aprender a ser professor. Diante de uma realidade complexa, muitas vezes o professor se desestrutura, pensa em desistir da profissão, sente-se como um estranho no ambiente escolar, duvida da sua competência e da importância da formação inicial. Enfim, para aqueles que permanecem, é uma fase que contribui de maneira singular para uma determinada forma de ser professor.

Em sua prática, os professores enfrentam situações que reclamam uma formação mais articulada com os desafios e dilemas que o processo de escolarização e as condições de exercício da docência impõem. Desse modo, pensamos ser relevante compreender como eles percebem as experiências vivenciadas ao longo da sua trajetória na carreira e particularmente aquelas relativas à iniciação na docência.

Compreender a aprendizagem profissional como um processo que não se encerra com a formação inicial, mas se dá ao longo da 
vida, que mobiliza diferentes saberes e experiências e envolve as dimensões pessoal e profissional, nos ajuda a caminhar no sentido de estabelecer diálogo com os contextos e práticas que marcam o exercício da docência.

Os estudos na área de formação de professores permitem compreender as possibilidades que esse campo apresenta para o desenvolvimento de experiências formativas, considerando o papel da universidade e a diversidade de experiências no percurso de desenvolvimento profissional.

A preocupação com a formação nas licenciaturas e a defesa da universidade como locus privilegiado de formação de professores motivaram este estudo. À universidade cabe rever, urgentemente, como tem se dado essa formação no interior dos cursos de licenciatura que oferece, pois "ao enfrentar esse desafio estará a Universidade, ela mesma, se formando". (MENEZES, 1987, p.123).

Compreendemos como uma tarefa urgente e complexa o pensar e propor alternativas de formação que atendam às necessidades do professor no exercício da profissão. Possivelmente, um passo importante seja buscar nos cursos de formação inicial a perspectiva dos alunos que já são professores. Diversos cursos de licenciatura de universidades brasileiras são freqüentados por um grupo específico, representado pelos alunos que aprendem a profissão docente na universidade e na escola ao mesmo tempo. O estudo desse perfil de estudante pode ampliar a nossa compreensão sobre o processo de formação de professores na universidade. A percepção desses alunos sobre o processo formativo pode fornecer elementos para se repensar a formação inicial e estreitar os vínculos dessa formação com a escola básica - local de exercício profissional -, pois esses alunos-professores atuam na escola cotidianamente e possuem uma experiência na docência que merece ser considerada.

\section{A PESQUISA: OUVINDO ALUNOS PROFESSORES}

Esta pesquisa insere-se no quadro teórico que foi delineado, concebendo a aprendizagem profissional da docência como um processo em que os saberes são contextualizados e influenciados pela trajetória de vida e de carreira. O professor, nessa perspectiva, torna- 
se o principal ator na construção de novos conhecimentos sobre a docência.

A possibilidade de efetuar essa análise da perspectiva dos alunos-professores ocorreu nos cursos de licenciatura em Letras e Matemática da Universidade Estadual do Sudoeste da Bahia (UESB), em duas turmas do $6^{\circ}$ semestre. Como parte de uma pesquisa mais ampla $^{1}$ (COSTA, 2005), este estudo busca compreender o que dizem os alunos-professores sobre a sua iniciação na docência. O objetivo é identificar elementos do percurso que possam contribuir para se repensar a formação inicial.

Como instrumento de coleta de dados foi utilizado questionário sobre formação e atuação docente dos participantes. Neste trabalho serão analisados os dados sobre a iniciação na docência. As respostas foram lidas buscando-se perceber aquilo que se apresentava como tendência e também aspectos pontuais que se mostrassem relevantes para compreender características do início da docência e oferecer subsídios para a formação de professores.

Os participantes do estudo foram 40 alunos-professores, sendo 27 do curso de Letras e 13 do curso de Matemática, que representavam $77 \%$ e $50 \%$ dos alunos das respectivas turmas. As suas falas são identificadas com as letras iniciais de cada curso, ou seja, L e M, e um número seqüencial.

\section{OS PARTICIPANTES: QUEM SÃO OS ALUNOS PROFESSO- RES DE LETRAS E MATEMÁTICA}

No curso de Letras, em relação ao sexo, a maioria dos alunosprofessores (vinte e três) é do sexo feminino, tendo somente quatro participantes do sexo masculino. Em Matemática ocorre o inverso: a maioria (oito) é do sexo masculino, havendo cinco participantes do sexo feminino. Essa relação aparece também quando observamos o total geral (alunos professores e alunos não professores) de cada turma.

Temos assim um quadro, nesse contexto, que pode repetir-se em outras universidades: um número significativo de mulheres ingressa

\footnotetext{
${ }^{1}$ COSTA, Josilene Silva da. A Aprendizagem da Docência na Perspectiva dos alunos professores. Dissertação de Mestrado -2005- DEME-UFSCar. O estudo buscou compreender como os alunosprofessores percebem a formação nas licenciaturas e as principais contribuições das mesmas para a aprendizagem e desenvolvimento profissional desse perfil de docente.
} 
nos cursos de licenciatura, que são aqueles considerados mais fáceis de obter aprovação no vestibular. São também os cursos de menor prestígio social e financeiro, e permitem o exercício da dupla jornada de profissionais e de donas de casa que muitas mulheres enfrentam. Tal quadro relaciona-se com a concepção do magistério como uma profissão construída histórica e socialmente como feminina. Existem diversos estudos (ALMEIDA, 1991; COSTA, 1996; LOURO, 1999) que discutem a questão de gênero e poder no magistério e é possível que essa questão esteja presente neste trabalho, embora não seja esse o eixo, o foco do estudo.

Percebe-se que a escolha dos cursos de licenciatura na instituição pesquisada sofre influência das poucas oportunidades de acesso ao ensino superior público na região (a maioria dos alunos sempre estudou na escola pública), das condições econômicas (a maioria trabalha e tem participação no orçamento doméstico) e da necessidade de qualificação profissional na área de atuação que, para um número significativo de alunos, é o ensino.

O tempo de exercício da docência dos participantes varia de um a 12 anos. Tanto em Matemática quanto em Letras a maioria tem até três anos de exercício na docência. Em Matemática, percebemos que mais da metade dos alunos-professores (62\%) está dentro do que se considera fase de iniciação, conforme Huberman (1992). Em Letras, $48 \%$ estão na fase de iniciação, aproximadamente $26 \%$ têm de quatro a seis anos de atividade docente, estando, segundo o autor, na fase de estabilização, consolidação de um repertório pedagógico; $26 \%$ têm de sete a 12 anos e estão na fase de diversificação, ativismo.

Quanto ao tempo de trabalho nas escolas em que estão atuando hoje, considerando os dois cursos, os dados apontam que a maioria dos alunos-professores tem até três anos na escola em que se encontra, ou seja, está iniciando no magistério e ainda em processo de aprendizagem das rotinas e da cultura do contexto de ensino. Eles se encontram no processo de formação acadêmica inicial e ao mesmo tempo já iniciaram suas trajetórias na docência, atuando em escolas da rede pública e particular, na Educação Básica.

O nível de atuação desses professores concentra-se no Ensino Fundamental de $5^{\mathrm{a}}$ a $8^{\mathrm{a}}$ séries (vinte e sete participantes), sendo que dezoito são do curso de Letras e nove do curso de Matemática. Dentre esses professores, no que se refere aos participantes do Curso de Matemática, três também atuam no Ensino Médio. O restante dessa 
turma atua somente no Ensino Médio. É interessante perceber que no curso de Letras, embora haja predominância de atuação no Ensino Fundamental, há certa diversificação nos níveis e espaços de atuação, pois temos alunos-professores atuando em cursos Pré-vestibulares (quatro), em Curso de Idiomas (um), em Seminário Teológico (uma), na Educação Infantil (uma), e no Ensino Médio (dois). Segundo conversa com a professora que coordenava o Curso de Letras no começo de 2004, os alunos são muito procurados pelas escolas e cursinhos e são considerados bons profissionais.

Percebe-se tanto entre os alunos-professores de Letras quanto entre os de Matemática que eles trabalham, em sua maioria, na área de conhecimento de sua formação (93\%). Contudo, declararam ter atuado em várias séries, tanto do Ensino Fundamental quanto do Ensino Médio, além de ter ministrado várias disciplinas fora da área de conhecimento de sua formação, principalmente os alunos-professores do curso de Letras. Parece que a formação na área de Matemática, para esses alunos-professores, restringe mais esse trânsito por disciplinas diversas.

Em relação à carga horária, a maioria dos participantes trabalha em torno de vinte horas semanais. Considerando isoladamente cada curso, entre os participantes do Curso de Letras, a maioria trabalha em torno de vinte horas; em Matemática, a maioria trabalha quarenta horas semanais.

\section{ANALISANDO OS DADOS: O INÍCIO DA DOCÊNCIA DOS ALUNOS PROFESSORES}

A questão das dificuldades vivenciadas no período de sua iniciação profissional na docência foi um aspecto que se revelou como tendência nas falas dos alunos-professores. Dificuldades que foram relatadas pela maioria dos participantes das duas turmas, referentes à metodologia, ao domínio do conteúdo, à articulação de teoria e prática, às condições de trabalho, entre outras, estão relacionadas a aspectos diversos que envolvem o trabalho do professor, podendo trazer insegurança e dúvida quanto às suas possibilidades de atuação, para aqueles que são iniciantes.

Como exemplo de um desses aspectos, observamos que 70\% dos participantes do estudo realizado trabalham em instituições pú- 
blicas de ensino. Constatamos, também, que em relação ao tipo de vínculo empregatício, muitos deles (a maioria) não são efetivos e sim contratados. É significativo o número de docentes (com formação e em processo de formação acadêmica inicial) nessa condição em instituições públicas de ensino, numa situação em que, para baratear a mão de obra, professores são contratados por tempo determinado, como mão-de-obra terceirizada, e nesse contrato estão excluídos os meses de férias e outros direitos trabalhistas.

Abusa-se do artifício da contratação do professor eventual, substituto, temporário e outras denominações. São professores que se deslocam de uma escola para outra, às vezes em curtos espaços de tempo, tendo que se colocar em situações de ensino bastante diferenciadas e responder às necessidades de cada contexto. Essa sensação de provisoriedade, o fato de se ver, de certa forma, numa condição de professor de "segunda categoria" pode deixar algumas marcas na construção da identidade desse professor. É possível observar essa realidade na seguinte fala:

Devido à falta de professores no mercado entramos em sala de aula no começo ou até antes de começarmos a cursar, além disso, as matérias didáticas e metodológicas são vistas no final do curso. $E$ realmente tomamos as iniciativas por conta própria (M39).

Apontando dificuldades do começo da docência, temos também os relatos de duas alunas-professoras que iniciaram sua vida profissional atuando na zona rural do município:

Iniciei trabalhando na zona rural, com classes multisseriadas. Foi um trabalho difícil, pois além da prática ser diferente da teoria estudada durante o magistério, as condições de trabalho eram precárias. (L7)

Quando iniciei na docência foi um pouco difícil, pois me submeti a um concurso no qual não tive a pontuação necessária para trabalhar na zona urbana, fui então para a zona rural. Foi meu primeiro ano de trabalho, o qual desempenhei com muita dificuldade, pois chegava muito cedo à escola e tinha que preparar merenda e isso foi terrível, não consegui fazer um bom trabalho. No ano seguinte fui transferida para a zona urbana, foi quando tudo melhorou.(L11) 
Percebemos nessas falas dificuldades relacionadas às condições de trabalho, o qual, no caso das depoentes (L7 e L11), era realizado no contexto do ensino na zona rural. Tais dificuldades são impostas pelos seguintes fatores, entre outros: carência de infra-estrutura; classes multisseriadas; falta de apoio pedagógico; distância do ambiente familiar (para alguns professores).

As falas nos fazem refletir sobre o abandono a que muitas vezes são submetidos os professores iniciantes, tendo que enfrentar situações bastante adversas logo no seu primeiro ano de trabalho.

Quando a aluna-professora diz "não tive pontuação necessária para trabalhar na zona urbana, fui então para zona rural", aparece a estratificação no destino concedido aos professores com menos pontos nas seleções para ingresso na carreira. Os colocados em classificações inferiores devem se deslocar para espaços também "menos privilegiados" de trabalho. Fica claro que os dois espaços - zona urbana e zona rural - não têm o mesmo valor social e profissional, e estar na zona rural pode ser vivido como punição, até se conseguir uma colocação melhor, como se vê neste depoimento: "No ano seguinte fui transferida para a zona urbana e tudo começou a melhorar".

Os professores iniciantes se deparam com uma situação vivenciada também pelos mais experientes, e que nos dois casos acarreta mal estar. No caso daquele que inicia sua vida profissional no magistério, isso pode marcar todo o seu percurso profissional. Estamos nos referindo à situação que Esteve (1995) chamou de "fragmentação do trabalho do professor", sobre a qual ele nos fala:

(...) o professor está sobrecarregado de trabalho, sendo obrigado a realizar uma actividade fragmentária lutando em frentes distintas, atendendo simultaneamente uma tal quantidade de elementos diferentes que se torna impossível dominar todos os papéis. A fragmentação do trabalho do professor é um dos elementos do problema da qualidade no sistema de ensino, paradoxalmente numa época dominada pela especialização. (p.108)

Além das tarefas relativas à organização do processo de ensino, a aluna-professora tinha que atender a outras demandas impostas pela precariedade das condições de trabalho: "Chegava muito cedo à escola e tinha de fazer a merenda e isso foi terrível" (L11). As dificuldades relatadas nos levam a refletir sobre a formação inicial e a carência 
de articulação desse espaço formativo com os diversos contextos de ensino onde, possivelmente, se dará a atuação do futuro professor.

Não estamos defendendo a aceitação de uma situação de precariedade, mas é sabido que as condições de trabalho no magistério são adversas e as modificações serão possíveis na medida em que sejamos capazes de refletir, pensar sistematicamente sobre a realidade, intervindo dentro da nossa competência profissional e política, identificando "os mecanismos do seu funcionamento, na procura de vias de recriação da profissão e de recomposição da sua imagem social". (CAVACO, 1995, p.160).

Ainda é comum na formação do professor a veiculação de uma imagem idealizada do ensino, onde a heterogeneidade, as divergências, os conflitos não são previstos. Não se aprende como planejar o trabalho numa realidade como, por exemplo, a realidade do ensino na zona rural em diversas regiões, onde predominam classes multisseriadas. Ou melhor, não se aprende a planejar, a agir frente à complexidade de uma escola que atende hoje a um grupo social que há algum tempo estava fora dela. O processo de massificação da escolarização alterou o perfil dos alunos da escola pública, a escola de elite virou escola de massas, como mostram Franchi (1995), referindo-se à realidade do Brasil, e Cortesão (2002), referindo-se a Portugal. A formação do professor ficou atrás no sentido de construir instrumentos mais adequados para compreender e intervir nesse contexto.

Falando desse descompasso entre formação e realidade, Esteve (1995, p.109) diz que "o professor novato sente-se desarmado e desajustado ao constatar que a prática real do ensino não corresponde aos esquemas ideais em que obteve a sua formação".

As dificuldades iniciais também podem ser percebidas na perspectiva da tensão entre teoria e prática. Parece que na iniciação profissional a teoria e a prática são percebidas como pólos desarticulados, até mesmo opostos no enfrentamento da realidade. O professor iniciante tem dificuldade de articular os instrumentos teóricos de que dispõe para, de alguma forma, interpretar as situações vividas e tomar as decisões que se fizerem necessárias em cada contexto. A visão, possivelmente decorrente da formação, de que a teoria automaticamente se aplicará à prática pacificamente, sem nenhum embate, desmorona. É o que observamos na reflexão:

Eu acho que se deve fazer um trabalho mais voltado para a reali- 
dade da sala de aula das escolas, de uma melhoria para o ensino fundamental e médio. (M37)

Talvez os cursos de formação inicial devessem tomar a prática dos professores com mais atenção e cuidado. É importante oportunizar a reflexão sobre a prática como espaço de produção de novos conhecimentos. Esse processo pressupõe aceitação e negação de modelos, o confronto de idéias e teorias em um movimento dinâmico que contribua para o desenvolvimento profissional do professor e para o processo de ensino e aprendizagem. Essa é uma questão que se coloca nos relatos sobre a iniciação:

Frustrante, porque percebi que na prática a teoria muitas vezes não se aplica. (L13)

No primeiro momento conflituosa, (...) tínhamos que 'jogar no lixo' tudo que foi ensinado anteriormente, pois a realidade não era bem aquela apresentada. (L1O)

(...) como a faculdade não nos prepara corretamente para a sala de aula, fui obrigado a recorrer ao meu conhecimento de mundo e tentar mudar o que eu considerava errado no modo de agir dos meus professores do passado (M4O).

O descompasso é evidente. Qual foi a realidade apresentada para esses alunos professores? Quais eram suas concepções e crenças sobre o ensino e o trabalho do professor na vivência desse começo? Como a formação inicial pode contribuir para que não pareça aos futuros professores que eles têm que "jogar no lixo" tudo que lhes foi ensinado? Como construir, nessa etapa da formação, uma base que permita ao professor uma inserção mais segura na carreira; uma compreensão mais situada do seu trabalho e da necessidade de se fazer escolhas teóricas e práticas; um desenvolvimento profissional mais sólido em termos de construção de um repertório de saberes e possibilidades de atuação? Como isso é possível? Acreditamos que essas questões são importantes e complexas, e responder às mesmas propositivamente ainda se constitui um desafio para a pesquisa na área de formação de professores.

O "choque de realidade" de que nos fala Huberman (1995, p.39), ao caracterizar a fase de iniciação na docência, faz-se presente 
nas falas dos participantes. A percepção de que nem tudo é previsível, controlável e harmonioso, desconcerta. A sensação de que a formação recebida é limitada e, muitas vezes, limitada naquilo que não poderia ser, desarruma o professor iniciante.

O caráter aplicacionista e absoluto da teoria, como sendo capaz de responder a todos os problemas da prática, não se confirma. O modelo de formação ainda vigente em certos contextos é pautado na racionalidade técnica, que concebe o professor como um técnico que enfrentará situações previsíveis e lineares, que reduz o trabalho docente a um trabalho basicamente instrumental, como nos mostram os estudos de Pérez Gomes (1992), Schön (1992) e outros. Essa concepção do trabalho docente não dá conta das situações singulares, complexas e dinâmicas que marcam a prática do professor enquanto prática social.

A partir dos relatos apresentados, é interessante refletir que, num primeiro momento, parece ocorrer uma negação por parte do professor iniciante de tudo que possa ter aprendido na formação inicial. Acreditamos que essa formação, ainda que apresente lacunas, propicia instrumentos importantes para a compreensão da realidade. Entretanto, para o professor iniciante, no meio de tudo que o cerca nesse momento, fica difícil fazer as articulações que deveriam ser feitas ao longo do curso. É interessante a metáfora que o participante usa para explicar isso:

(...) a experiência traz ela [a pessoa] para a realidade, ela vive assim num mundo como se ela chegasse até certo ponto era tudo azul, aí dá um passo à frente e escurece tudo (...) Então tenho que voltar e procurar onde é que é o caminho que tem luz, entendeu? (M39)

Discutindo sobre as dificuldades pelas quais passam os professores iniciantes e sobre como essas dificuldades podem justificar um percurso que leva à descrença, ao desencanto, à falta de desejo nas questões da profissão, Cavaco (1995) afirma:

Os professores no início de carreira não têm o domínio cognitivo das estruturas profissionais, nos seus diferentes níveis, o que os incita a tomar o mundo profissional tal como é, ou parece ser, mais do que rebelarem-se contra ele, a oporem-lhe outros possíveis, diferentes ou até antagônicos.(p.165) 
Parece ser pertinente afirmar que os cursos de formação inicial e continuada não podem desconsiderar essa questão nas suas propostas de formação.

Ainda analisando aquilo que se apresentou como tendência nas falas, percebemos que a dificuldade inicial refere-se também à questão da relação conteúdo e metodologia e aparece na fala de professoras, que dizem:

Difícil, pois saí do antigo científico e não possuía metodologia e didática nenhuma para atuar, apesar de saber o conteúdo. (L2)

(...) Saber matemática não é garantia de saber ensinar matemática (M28).

Os alunos professores percebem que "saber o conteúdo" é importante, mas não é suficiente. Os aspectos didático-metodológicos e o domínio de conteúdo parecem adquirir importância maior para quem já ensina. As questões enfrentadas no exercício da profissão podem fazer com que esses alunos queiram meios e instrumentos que os ajudem a lidar com as situações ou, quem sabe, a ver essas situações sendo objeto de análise dentro do curso.

Essa é uma questão importante na formação inicial e continuada de professores. O domínio da área de conhecimento e o como fazer a transposição desse conhecimento para conteúdo de ensino é uma forma de construir uma identidade profissional, é fortalecer-se naquilo que, entre outros elementos, constitui o trabalho do professor: o ensino e a aprendizagem de conteúdos intencionalmente sistematizados. $\mathrm{O}$ estudo de Moraes (2006) também evidencia esse aspecto em relação aos professores iniciantes no curso pré-vestibular investigado, quando mostra que eles consideraram prioritário equacionar questões relativas ao próprio domínio dos conteúdos. Após considerarem vencida essa etapa, passaram a analisar diferentes aspectos do processo de ensino e aprendizagem, como a relação com os alunos, o planejamento de estratégias de ensino, a avaliação, entre outros.

Esse processo envolve o saber e o saber-fazer e merece atenção na formação do professor, como colocam Carvalho e Perez (2001): "Todos os trabalhos de pesquisa existentes mostram a gravidade causada por uma carência de conhecimentos da matéria pelo professor, transformando-o em um transmissor mecânico dos conteúdos de 
livros-textos". (p.109)

Na prática docente, saberes diversos se fazem presentes e são mobilizados pelo professor. Aí se incluem os saberes específicos de uma determinada área de conhecimento e também a forma de ensinálos como conteúdos disciplinares. A prática docente não se constitui de um único saber nem de saberes isolados, mas constitui-se pela articulação de saberes oriundos de diversas fontes e que estão de tal forma imbricados que não podemos precisar exatamente onde termina um e nasce o outro. Tem a ver com a experiência pessoal e profissional do professor e também com uma concepção mais abrangente e complexa do que venha a ser o papel do professor e da escola, como nos mostram Nóvoa (1995), Tardif et al. (1991) e Tardif \& Raymond (2000).

Acreditamos que a formação inicial deve construir junto aos alunos a compreensão de que o saber e o saber-fazer são processos que implicam aprendizagem permanente. A partir de uma base sólida, esses saberes deverão ser reelaborados e ressituados continuamente, dialogando com outros saberes e com a prática. Isso demanda do professor uma postura mais flexível diante da formação, da profissão e do conhecimento.

Encontramos falas em que a dificuldade inicial é percebida, porém colocada de uma forma que, nos parece, é menos sofrida. Acreditamos que essa dificuldade pode estar relacionada com certas predisposições pessoais, com as condições de trabalho no local onde essa iniciação se faz e também com o tempo de exercício do magistério. Em relação ao tempo, a distância da situação pode contribuir na forma de representá-la. Tomamos como exemplo a fala de duas professoras, uma com dez e a outra com doze anos de profissão. Dentre os participantes, elas são as que têm mais tempo de trabalho:

Comecei muito cedo, com pouca experiência e esta foi adquirida ao longo dos tempos, sempre procurando o bom senso. (L6)

No início, a minha maior dificuldade foi lecionar várias disciplinas em várias séries, uma salada; o início é sempre difícil, por conta da inexperiência, insegurança, porém a vontade de acertar prevalece $e$, gradualmente, as dificuldades são vencidas. (L5)

A visão de que as dificuldades são superadas "gradualmente", 
o papel do tempo na aquisição da experiência e a disponibilidade em acertar, estão presentes nessas falas.

Huberman (1995) nos diz que, mesmo que os achados mostrem que os professores vivenciam "crises" durante a carreira, essas crises são objetivamente de natureza diferente, elas têm antecedentes diferentes e são percebidas de forma muito diversa pelos professores.

Dentre os participantes, um grupo revela aspectos positivos sobre o início da docência. Destacam-se a alegria pela descoberta da profissão e um sentimento de tranqüilidade nessa fase. Apresentamos como exemplo disso a fala de uma professora que parece ter vivido a "descoberta" na sua iniciação. Ela, que tem três anos de docência, relata:

Fiquei nervosa, perdida e ao mesmo tempo me encontrei profissionalmente quando fui dar aula. (L12)

Essa professora iniciou seu percurso na docência junto com o ingresso na licenciatura. Sua fala nos ajuda a perceber que o "choque de realidade" vivido - como se pode observar em "fiquei nervosa, perdida" - fez-se acompanhar do que Huberman (1995) descreve como sendo o aspecto da "descoberta", que traduz o entusiasmo, a experimentação, o sentir-se parte de um grupo profissional, podendo assim contribuir para a permanência na profissão.

Outros dois participantes, que também iniciaram a docência junto com o ingresso na licenciatura, não fazem referência a dificuldades. Parece que o aspecto da "descoberta" colocou-se como dominante para eles:

Foi uma excelente oportunidade para que eu conhecesse a convivência entre professor e aluno, agora na visão de professora. Foi uma experiência maravilhosa e ao mesmo tempo muito trabalhosa. Fiquei radiante por poder ensinar algo novo a alguém. (L9)

Eu achei maravilhosa, pois estreei numa turma de Pré-vestibular, onde a maturidade dos alunos ajudou bastante o meu trabalho. Hoje, após dois anos, posso constatar as mudanças super positivas que já aconteceram em minha carreira. A cada aula eu estou me renovando, ficando mais seguro e, conseqüentemente, aprimorando meu conhecimento. Hoje eu já tenho um certo domínio de classe e até já me encorajei a fazer algumas brincadeiras com os poemas 
para descontrair os meus alunos.(L4)

Certas características pessoais podem contribuir para que as situações vividas - ter disponibilidade para lidar com o imprevisto; enfrentar desafios; gostar de aprender, perceber-se no processo, entre outras - sejam encaradas de forma positiva, ao mudar ou alternar os papéis, já que aqueles que as vivenciam ainda são alunos na licenciatura.

A segunda fala refere-se a uma "estréia", expressando com certo entusiasmo a percepção do seu processo de desenvolvimento profissional: aquisição de mais segurança; capacidade de ousar movimentar-se na proposição de atividades, no relacionamento com a turma. Essa fala é de um dos participantes do sexo masculino do curso de Letras. Sua iniciação docente ocorreu em curso pré-vestibular e por essa e outras falas percebemos que o iniciar com turmas mais maduras foi menos desestabilizador para os professores.

Chama atenção o fato de alguns dos poucos participantes do sexo masculino não estarem no Ensino Fundamental, como a maioria das mulheres, e sim em cursinhos onde a remuneração é melhor, a exigência no nível dos conteúdos maior e o reconhecimento profissional mais imediato. Como se afirmou anteriormente, as questões de gênero e poder marcam a carreira do magistério, mas essa discussão foge ao objetivo do nosso estudo.

Os resultados evidenciam a importância de suportes institucionais e de espaços de troca e partilha no curso de formação, a necessidade de acesso a informações que contribuam para a aprendizagem e para o desenvolvimento profissional do professor de maneira geral e, principalmente, para o iniciante. A fala de uma professora que tem dois anos de exercício na docência revela a importância desses espaços:

Mas com o passar do tempo, com os conhecimentos adquiridos na universidade, bem como, a orientação de coordenadores e outros professores, pude desenvolver a cada dia a minha docência. (L16)

Sobre essa questão, Cavaco (1995) nos afirma ser importante:

(...) encontrar nos primeiros tempos de profissão, redes de informa- 
ção actualizada que facilitem a apropriação criticamente reflectida das diversas competências profissionais. De momento, o acesso à informação é fortemente assimétrico. Por razões socioeconómicas, de origem, ou pelo nível cultural dos grupos de pertença, alguns, poucos, encontram-se próximos de centros difusores de conhecimento - instituições e pessoas - que lhes podem facilitar instrumentos teóricos e operatórios susceptíveis de apoiar as suas práticas de forma pertinente e adequada (p. 167).

Consideramos que é tarefa da Universidade prover esses suportes para os professores da escola básica. A formação inicial e continuada deve ocorrer de forma estreitamente articulada, considerando o contexto, a escola, o professor e suas necessidades formativas.

\section{CONCLUINDO...}

Analisando as experiências de iniciação na docência dos alunosprofessores das licenciaturas em Letras e em Matemática, encontramos importantes contribuições para a reflexão sobre a formação nos cursos de licenciatura. Os relatos apontam aspectos relacionados à aprendizagem da docência que podem oferecer suportes para um enfoque diferenciado na formação profissional dos professores.

A experiência vivenciada por esses alunos de iniciação na docência e formação acadêmica paralelas, mostra a necessidade de uma articulação mais estreita entre teoria e prática, num movimento dinâmico em que o centro é o cotidiano da escola, as rotinas, as práticas, os conteúdos, os sujeitos, a sua problemática.

As dificuldades relacionadas ao planejamento e desenvolvimento do ensino em realidades complexas, envolvendo o atendimento a um grande número de solicitações e de tarefas, as diferenças entre o aluno real e um ideal de aluno presente no imaginário, o sentimento de insegurança, a consciência do precário domínio do conteúdo a ensinar, a necessidade de novas metodologias de ensino, colocam em cheque a formação de professores nas licenciaturas.

Tais dificuldades são significativas para a maneira de ser e de estar na profissão docente. Quando 70\% dos participantes atuam na rede pública, no Ensino Fundamental, na maioria das vezes com contratos temporários, sem vínculo profissional, não podem ser 
ignoradas as condições de trabalho dos professores iniciantes e dos professores da escola básica de uma maneira geral. Tal estudo mostra a necessidade de suportes institucionais ao trabalho do professor, seja ele iniciante ou experiente, e acreditamos que a universidade precisa colocar-se melhor diante dos desafios que essa tarefa exige.

A vivência do "choque de realidade" e também do prazer de sentir-se professor aponta para a construção de uma atitude profissional que precisa ser fomentada durante a formação, considerando a imprevisibilidade e a complexidade do trabalho docente. Mostra a importância da disponibilidade para refazer caminhos, enfrentar desafios, num processo constante de reinvenção da profissão e de si mesmo como professor. A influência das experiências pessoais no desenvolvimento profissional docente mostra que é fundamental conhecer quem é esse professor em formação, quais são suas experiências, suas concepções e crenças sobre o ensino, a aprendizagem, a escola e o conhecimento.

As reflexões indicam que é importante aprender, sistematicamente, a trabalhar em grupo na formação inicial, numa perspectiva política e pedagógica de como precisa ser o trabalho docente na escola, principalmente na escola pública, que é o local de trabalho de uma parcela significativa dos alunos das licenciaturas. Mostram, também, que é importante para o professor aprender a pesquisar e construir conhecimento sobre o ensino nos diversos contextos, compreender os desafios do seu trabalho na perspectiva da trajetória da educação no Brasil e da realidade singular em que o mesmo se encontra. Aprender que o seu local de trabalho pode ser reconstruído e de que é possível ter prazer na escola.

A compreensão da formação como um processo que ocorre ao longo da carreira e da vida nos ajuda a entender os limites e a incompletude da formação inicial. Este estudo evidencia que essa etapa do processo de formação docente é importante e precisa ser potencializada naquilo que lhe compete, ou seja, no domínio "de uma bagagem sólida nos âmbitos científico, cultural, contextual, psicopedagógico e pessoal" (IMBERNÓN, 2000, p.60-61).

Evidencia, também, que os conteúdos da formação de um professor não são só acadêmicos e que os conteúdos acadêmicos precisam dialogar, interagir com a vida real das escolas, dos alunos e dos professores. Em síntese, reafirma que a universidade precisa ultrapassar a perspectiva certificatória e assumir uma postura mais 
solidária e mais comprometida com a escola básica e com o professor que se faz cotidianamente dentro dela.

\section{REFERÊNCIAS}

ALMEIDA, C. C. de. O magistério feminino laico no século XIX. Teoria e Educação, n.4, Porto Alegre: Pannonica Editora ( 1991).

CANDAU, V. M. Universidade e formação de professores: que rumo tomar? In: CANDAU, Vera Maria (org.). Magistério: construção cotidiana. Petrópolis: Vozes (1999).

CARVALHO, A. M. P. e PEREZ, D. G. O saber e o saber fazer do professor. In: CASTRO, A. D. de \& CARVALHO, A. M. P. (orgs.). Ensinar a ensinar: didática para uma escola fundamental e média. São Paulo: Pioneira Thomson Learning, 2001.

CAVACO, M. H. Ofício do Professor: o tempo e as mudanças. In: NÓVOA, A. (org.). Profissão Professor. Porto Editora, 1995, p.155-191.

CORTESÃO, L. Ser professor: um ofício em risco de extinção? São Paulo, Cortez, 2002.

COSTA, J. S. da. A aprendizagem da docência na perspectiva dos alunosprofessores. 2005, Dissertação (Mestrado em Educação), Centro de Ciências Humanas, Universidade Federal de São Carlos, SP.

COSTA, M. V. Gênero, profissionalismo e formação docente: complexas conexões. In: Encontro Nacional de Didática e Prática de Ensino - ENDIPE, 8.,1996, Florianópolis. Anais... Florianópolis : UFSC, 1996.

ESTEVE, J. M. Mudanças sociais e função docente. In: Nóvoa, Antonio (org). Profissão Professor. Porto Editora (Coleção Ciências da Educação), 1995.

FRANCHI, E. P. A insatisfação dos professores: conseqüências para a profissionalização. In: FRANCHI, E. P. (org.). A causa dos professores. Campinas, Papirus, 1995. p.17-90.

GOMES, A. P. O pensamento prático do professor: a formação do professor como profissional reflexivo.In: NÓVOA, A. (org.) Os professores e sua formação. Lisboa: Publicações Dom Quixote, 1992. p.95-114.

HUBERMAN, M. O ciclo de vida profissional dos professores. In: NÓVOA, A. (org.). Vidas de professores. Porto Editora, 1995, p.31-61.

IMBERNÓN, F. Formação docente e profissional: formar-se para a mudança e a incerteza. São Paulo: Cortez, 2000. (Coleção Questões da Nossa Época, 
v.77).

KNOWLES J. G., COLE, A. L., PRESSWOOD, C. Through Preservice Teachers' eyes: exploring field experiences through narrative and inquiry. N.Y.: Macmillan College Publishing Company, 1994.

LOURO, G. L. Gênero, sexualidade e educação: uma perspectiva pósestruturalista. 3. ed. Petrópolis, RJ: Vozes, 1999.

MARCELO, C. Pesquisa sobre formação de professores: o conhecimento sobre o aprender a ensinar. Revista Brasileira de Educação, n.9, S. Paulo, ANPEd, set./out./nov. de 1998, p.51-75.

MENEZES, L. C. Formar professores: tarefa da universidade. In: CATANI, D. B. et alii(orgs.). Universidade, escola e formação de professores. S. Paulo, Brasiliense, 1987, p. 115-125

MIZUKAMI, M. G. Docência, trajetórias pessoais e desenvolvimento profissional. In: MIZUKAMI, M. G. N. \& REALI, A. M. M. (orgs.). Formação de professores: tendências atuais. São Carlos: EDUFSCar, 1996. p.59-91.

MIZUKAMI, M. G. Casos de Ensino e aprendizagem profissional da docência. In: ABRAMOWICZCZ, A. \& MELLO, R. R.(orgs.). Educação: pesquisas e práticas. São Paulo, Papirus Editora, 2000. p.139-161

MIZUKAMI, M. G. N. E REALI, A. M. M. (orgs.). Aprendizagem profissional da docência: saberes contextos e práticas. São Carlos/SP, EDUFSCar, 2002.

MORAES, A. C. Aprendizagem da docência: um estudo com professores do curso Pré-Vestibular da UFSCar. São Carlos, 2005, Dissertação (Mestrado em Educação), Centro de Educação e Ciências Humanas, Universidade Federal de São Carlos, SP.

NÓVOA, A. Formação de professores e profissão. In: NÓVOA, A. (org.). Os professores e sua formação. Lisboa: Publicações Dom Quixote, 1992.

NÓVOA, A. Os professores e as histórias da sua vida. In: NÓVOA, A. (org.). Vidas de Professores. Porto Editora, 1995, p.11-25.

PEREIRA, J. E. D. Formação de professores: pesquisa, representações e poder. Belo Horizonte: Autêntica, 2000. (Coleção Trajetória, 4).

SCHON, D. A. Formar professores como profissionais reflexivos. In: NÓVOA, A. (org.). Os professores e sua formação. Lisboa: Publicações Dom Quixote, 1992.

SANTOS, L. C. P. Formação de professores e qualidade de ensino. In: SOARES, M. B., KRAMER, S., LUDKE, M. et al. Escola Básica. Campinas: SP, Papirus, 1994 (Coletânea C.B.E.). 
SANTOS, L. C. P. Pluralidade de saberes em processos educativos. In: CANDAU, V. M. (org.). Didática, currículo e saberes escolares. Rio de Janeiro: DPEA, 2000.

TARDIF, M. e RAYMOND, D. Saberes, tempo e aprendizagem no magistério. Educação e Sociedade, ano XXI, N.73, Dezembro 2000.

TARDIF, M., LESSARD, C., LAHAYE, L. Os professores face ao saber: esboço de uma problemática do saber docente. Teoria e Educação, n. 4, Porto Alegre: Pannonica Editora, 1991.

TARDIF, M. Saberes profissionais dos professores e conhecimentos universitários. Revista Brasileira de Educação, n.13, São Paulo, ANPEd, Jan/Fev/ Mar/Abr. de 2000, p.5-24.

Encaminhado em: 14/03/07

Aceito em: 10/05/07 